\title{
Bilateral congenital dacryocystoceles with intranasal mucoceles in the neonate: Case report and review of literature ${ }^{*}$
}

\author{
Kenneth M. Wong ${ }^{1}$, Adrian W. Jachens ${ }^{2}$, John Bortz ${ }^{2}$, Augustine Moscatello ${ }^{3}$ \\ ${ }^{1}$ Department of Otolaryngology-Head and Neck Surgery, New York Eye and Ear Infirmary, New York, USA \\ ${ }^{2}$ Department of Ophthalmology, Westchester Medical Center, New York, USA \\ ${ }^{3}$ Department of Otolaryngology-Head and Neck Surgery, Westchester Medical Center, New York, USA \\ Email: kwong@nyee.edu
}

Received 21 March 2012; revised 9 May 2012; accepted 18 May 2012

\begin{abstract}
Congenital dacryocystoceles with intranasal mucoceles are an uncommon entity. The overwhelming majority of reported cases are unilateral in nature. We present a rare case of a neonate with bilateral congenital dacryocystoceles with intranasal mucoceles. Management of dacryocystoceles includes medical and surgical treatment. Literature review revealed 186 reported cases of congenital dacryocystoceles with 82 associated with intranasal mucoceles. Prevalence rates ranged between $11 \%$ to $100 \%$. Our case highlights the importance of nasal endoscopy in the work up and identification given the high prevalence rate of intranasal mucocele component in patients with congenital dacryocystoceles.
\end{abstract}

Keywords: Dacryocystocele; Intranasal Mucocele; Amniotocele; Lacrimal Sac Cyst

\section{INTRODUCTION}

Although congenital obstruction of the nasolacrimal duct is a common event, associated darcyocystoceles are less frequent. First described by Silverman in 1933 [1], it has been referred to by a variety of terms including lacrimal mucocele, lacrimal sac mucocele, dacryocystocele, dacryocele, lacrimal sac cyst, or amniotocele but is generally described as a mucous cyst created by a distended lacrimal sac filled with mucous secreted by the lacrimal sac goblet cells [2]. The nasolacrimal duct system is drained by two horizontal canaliculi which empty into the lacrimal sac which then drains into the nasal cavity. Congenital dacryocystoceles are believed to arise from obstruction proximally at the valve of Rosenmuller and distally at the valve of Hasner. This leads to accumula-

\footnotetext{
${ }^{*}$ The authors indicated no potential conflicts of interest or financial contributions.
}

tion of fluid in the nasolacrimal duct system and distention of the lacrimal sac which presents clinically as a bluish mass inferior to the medial canthal tendon in newborns and infants [3]. Intranasal mucoceles can be associated with dacryocysteoceles when the obstructed nasolacrimal duct causes a distention of nasal mucosa into the nasal cavity most commonly at the level of the occluded valve of Hasner. With nasal examination, these nasal mucoceles can be observed extending below the inferior turbinate. The majority of reported cases of congenital dacryocystoceles with intranasal mucoceles have been unilateral. This is a rare case of bilateral congenital dacryocystoceles with intranasal mucoceles in the neonate.

\section{CASE REPORT}

The patient presented to the clinic as a 19 day old Hispanic female with a history of bilateral palpable fluctuant blue masses in the medial canthi. Three days prior to presentation the left mass became indurated and erythematous with mucopurulent discharge from both the superior and inferior left puncta. The patient was admitted to the hospital and started on ampicillin/sulbactam for the treatment of left dacryocystitis. After two days of intravenous antibiotics, the erythema and induration resolved. The patient was then brought to the operating room for an exam under anesthesia and surgical management. The bilateral medial canthal masses were examined and all four puncta were dilated with a punctal dilator. In the same setting, an endoscopic nasal exam was performed and large cystic lesions were noted bilaterally in the anterior inferior meatus (Figures 1 and 2). Nasolacrimal duct probes were advanced through the distal obstruction displacing the cysts. Both cysts were removed endoscopically and sent for histological studies. Both lacrimal sacs were decompressed and the contents were sent for microbiology culture. The probes were then passed 


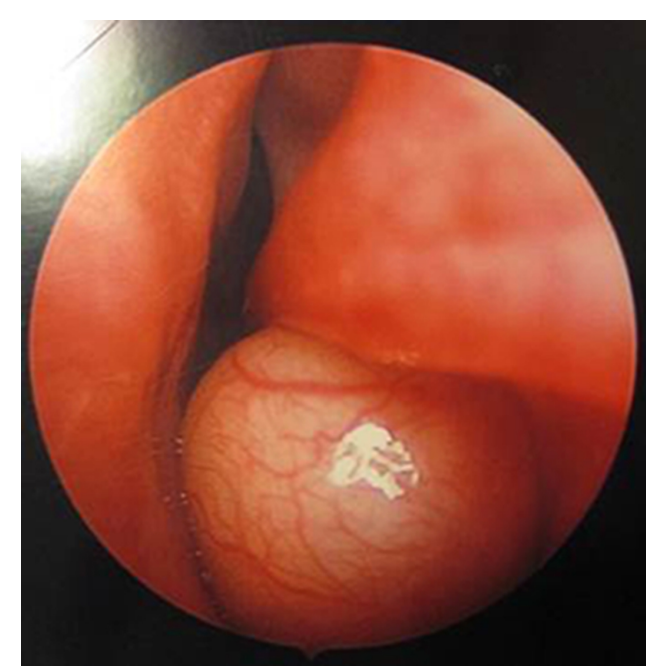

Figure 1. Endoscopic view of left intranasal cyst.

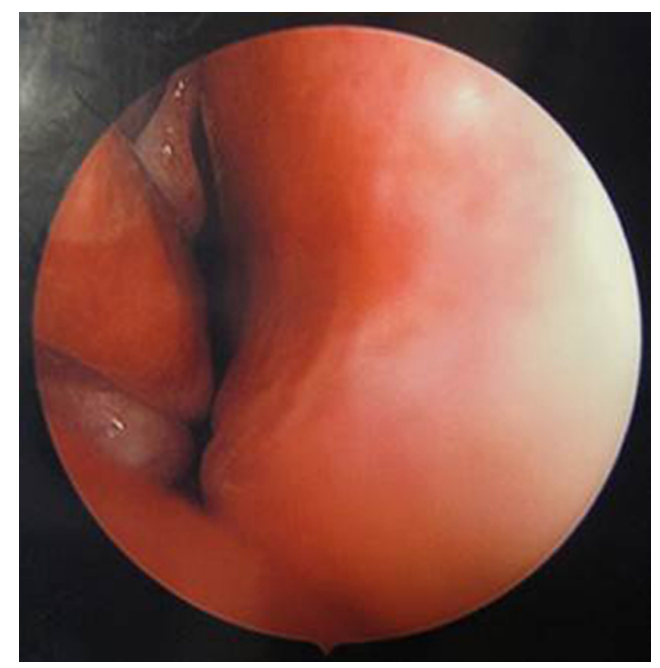

Figure 2. Endoscopic view of right intranasal cyst.

without difficulty and were visualized in the inferior meatus on both sides. Lacrimal stents were placed bilaterally and secured with a single suture. Post-operative exams showed resolution of both the medial canthal masses and left dacryocystitis. The cultures of the mucopurulent discharge grew Streptococcus Viridans. Histological analysis of the excised cysts confirmed lacrimal cyst tissue with mild acute and chronic inflammation. The patient has been followed in clinic for nine months with physical and endoscopic exams without evidence of return of dacryocystocele or nasal cysts. Nasolacrimal duct stents were removed after six months of follow up.

\section{DISCUSSION}

The presentation of congenital dacryocystoceles can occur within weeks to months of birth and is associated with epiphora, excess discharge, and a pink or bluish mass inferior to the medial canthus. The differential diagnosis includes encephalocele, meningoencephalocele, nasal glioma, capillary hemangioma, solid dermoid, dermoid cyst, and lymphangioma [3]. Neonates are obligate nose breathers and an intranasal cyst causing nasal obstruction could cause respiratory distress [4]. If respiratory distress is present, other causes such as choanal atresia or pyriform aperture stenosis should be ruled out. Diagnostic studies such as computed tomography (CT) or magnetic resonance imaging (MRI) can be useful in these circumstances if the diagnosis of dacryocystocele is uncertain [5]. The true prevalence of intranasal cysts associated with dacryocystoceles is unknown. A literature search revealed 82 out of 186 reported cases of intranasal cysts associated with dacryocystoceles, and prevalence rates ranged between $11 \%$ and $100 \%$. The summary of reported cases is illustrated in Table 1.

The management of dacryocystoceles consists of both medical and surgical treatment. Dacryocystoceles can be divided into uncomplicated and complicated cases based on clinical presentation. Uncomplicated cases can be treated initially with medical management consisting of warm compresses, lacrimal massage, and topical antibiotics. Schnall and Christian reported a $76 \%$ resolution rate within six days of treatment on medical management alone for uncomplicated dacryocystoceles [6]. Intravenous antibiotics are reserved for actively infected dacryocystoceles. Complicated cases can occur secondary to acute or chronic dacryocystitis, cellulitis, or nasal obstruction from an intranasal cyst component [7]. Sepsis, meningitis, and even brain abscess can be sequelae of an infected dacryocystocele [5]. Prompt surgical management is indicated when medical management has failed. Surgical management consists of three options: 1) Lacrimal probing only; 2) Nasal endoscopy with cyst marsupialization; or 3) Combined approach [3]. Wong and VanderVeen reported 36 out of 46 cases (78\%) requiring surgical intervention with no complications. The only

Table 1. Prevalence of intranasal cysts associated with dacryocystoceles.

\begin{tabular}{lccc}
\hline & $\begin{array}{c}\text { Intranasal } \\
\text { cysts }\end{array}$ & Dacryocystoceles & $\begin{array}{c}\text { Prevalence } \\
(\%)\end{array}$ \\
\hline Levin, et al. [2] & 23 & 24 & 96 \\
Shashy, et al. [3] & 7 & 10 & 70 \\
Paysse, et al. [5] & 23 & 30 & 77 \\
Wong, et al. [8] & 8 & 46 & 17 \\
Shekunov, et al. [9] & 3 & 9 & 33 \\
Hain, et al. [10] & 5 & 5 & 100 \\
Mansour, et al. [11] & 6 & 54 & 11 \\
Cavazza, et al. [12] & 1 & 5 & 20 \\
Thomas, et al. [13] & 6 & 8 & 75 \\
\hline
\end{tabular}


failures were those cases in which there was an undiagnosed intranasal cyst [6]. Levin reported on 24 cases all undergoing combined lacrimal probing and endoscopic approach with no surgical complications. At follow up, 23 out of 24 (96\%) had complete clinical cure. Based on success rate and lack of surgical complications, they advocate earlier surgical treatment of uncomplicated dacryocystoceles [2].

\section{CONCLUSION}

Congenital dacryocystocele is a relatively uncommon entity. Bilateral presentation with associated intranasal mucoceles is an extremely rare occurrence. Prevalence rates range between $11 \%$ to $100 \%$ depending on which case series are studied. Cases can be uncomplicated or complicated and may require both medical and surgical management. Primary care pediatricians and neonatologists should be aware of the clinical presentation and referral to the appropriate care provider is warranted including both ophthalmology and otolaryngology specialties. If an intranasal cyst component is present, then a multidisciplinary approach can be performed for surgical management including lacrimal probing and endoscopic marsupialization. This case highlights the importance of utilizing nasal endoscopy in the clinical evaluation to ensure proper diagnosis and management of this condition.

\section{REFERENCES}

[1] Silverman, S. (1933) Microphthalmos with congenital defect of the lacrimal apparatus. British Journal of Ophthalmology, 17, 333-351. doi:10.1136/bjo.17.6.351

[2] Levin, A.V., Wygnanski-Jaffe, T., Forte, V., et al. (2003) Nasal endoscopy in the treatment of congenital lacrimal sac mucoceles. International Journal of Pediatric Otorhinolaryngology, 67, 255-261. doi:10.1016/S0165-5876(02)00379-8
[3] Shashy, R.G., Durairaj, V.D., Holmes, J.M., et al. (2003) Congenital dacryocystocele associated with intranasal cysts: Diagnosis and management. Laryngoscope, 113, 37-40. doi:10.1097/00005537-200301000-00007

[4] Teymoortash, A., Hesse, L., Werner, J.A., et al. (2004) Bilateral congenital dacryocystocele as a cause of respiratory dis-tress in a newborn. Rhinology, 42, 41-44.

[5] Paysse, E.A., Coats, D.K., Bernstein, J.M., et al. (2000) Management and complications of congenital dacryocele with concurrent intranasal mucocele. Journal of AAPOS, 4, 46-53. doi:10.1016/S1091-8531(00)90011-9

[6] Schnall, B.M. and Christian, C.J. (1996) Conservative treatment of congenital dacryocele. Journal of Pediatric Ophthalmology \& Strabismus, 33, 219-222.

[7] Cunningham, M.J. (2006) Endoscopic management of pediatric nasolacrimal anomalies. Otolaryngologic Clinics of North America, 39, 1059-1074. doi:10.1016/j.otc.2006.07.004

[8] Wong, R.K. and VanderVeen, D.K. (2008) Presentation and management of congenital dacryocystocele. Pediatrics, 122, e1108-e1112. doi:10.1542/peds.2008-0934

[9] Shekunov, J., Griepentrog, G.J., Diehl, N.N., et al. (2010) Prevalence and clinical characteristics of congenital dacryocystocele. Journal of AAPOS, 14, 417-420. doi:10.1016/j.jaapos.2010.07.006

[10] Hain, M., Bawnik, Y., Warman, M., et al. (2011) Neonatal dacryocele with endonasal cyst: Revisiting the management. American Journal of Otolaryngology, 32, 152155. doi:10.1016/j.amjoto.2009.11.009

[11] Mansour, A.M., Cheng, K.P., Mumma, J.V., et al. (1991) Congenital dacryocele: A collaborative review. Ophthalmol, 98, 1744-1751.

[12] Cavazza, S., Laffi, G.L., Lodi, L., et al. (2008) Congenital dacryocystocele: Diagnosis and treatment. Acta Otorhinolaryngologica Italica, 28, 298-301.

[13] Thomas, S.A., Drack, A.V., Sands, R.E., et al. (2000) Clinical and histopathologic features of congenital dacryocysto-celes associated with intranasal cysts. Journal of AAPOS, 4, 46-63. 